\title{
Pengaruh Penambahan Bahan Campuran Dalam Proses Biogas Limbah Cair Tahu
}

\author{
Ali Wahyudi ${ }^{1)}$, Hesti Istiqlaliyah ${ }^{2)}$, M. Muslimin Ilham ${ }^{3)}$. \\ 1), 2), 3)Program Studi Teknik Mesin, Universitas Nusantara PGRI Kediri, Jawa \\ Timur, Indonesia \\ E-mail: ${ }^{1)}$ aliwahyudi386@gmail.com, ${ }^{2}$ hestiisti@unpkediri.ac.id, \\ 3)im.muslimin@unpkediri.ac.id.
}

\begin{abstract}
Abstrak
Salah satu alternatif penanganan limbah industri tahu yang saat ini banyak diteliti dan dikembangkan adalah mengubah limbah industri tahu menjadi bahan bakar alternatif berupa biogas. Mekanisme pembuatan biogas dengan proses anaerobic digestion menggunakan bahan baku limbah cair tahu dengan biodigester berkapasitas 200 liter. Bahan baku limbah cair tahu dicampurkan dengan variasi komposisi yang berbeda ialah komposisi alami, komposisi organik dan komposisi kimia. Komposisi masing-masing berupa kotoran sapi 20 kg, cairan kimia EM4 2 liter dan alami dengan tidak ada penambahan. Bahan baku yang sudah dicampurkan selanjutnya dimasukkan ke dalam ruang digester. Lamanya waktu fermentasi selama 20 hari hingga di dapatkan data penelitian mengenahi temperatur dan tekanan biogas. Hasil dari penelitian ini adalah adanya peningkatan temperatur dan tekanan pada proses anaerobic digestion. Dimana peningkatan tertinggi terdapat pada komposisi kimia pada hari ke 17 hingga hari ke 20 dengan temperatur $30 \square \mathrm{C}$ dan tekanan maksimum adalah $18 \mathrm{~cm}=0,018 \mathrm{~N} / \mathrm{m} 2$ diperoleh dari selisih kolom air. Komposisi organik dengan temperatur $29^{\circ} \mathrm{C}$ dan tekanan selisih kolom air $17 \mathrm{~cm}=$ $0,017 \mathrm{~N} / \mathrm{m} 2$. Hasil terendah terdapat pada komposisi alami dengan temperatur $26^{\circ} \mathrm{C}$ dengan tekanan selisih kolom air $4 \mathrm{~cm}=0,04 \mathrm{~N} / \mathrm{m} 2$. Jika tidak menggunakan bahan campuran maka biogas akan lama diproduksi.
\end{abstract}

Kata Kunci: Limbah cair tahu, Variasi komposisi, Anaerobic digestion, Energi alternatif.

\section{Abstract}

One alternative to tofu industry waste handling which is currently being researched and developed is to change tofu industry waste into alternative fuels in the form of biogas. The mechanism of making biogas by anaerobic digestion process using tofu liquid waste raw material with a 200 liter capacity biodigester. The raw material for tofu liquid waste mixed with different composition variations is natural composition, organic composition and chemical composition. Each composition consists of $20 \mathrm{~kg}$ cow dung, 2 liter EM4 chemical liquid and natural with no additions. The raw material that has been mixed is then put into the digester chamber. The length of time of fermentation for 20 days to get research data about biogas temperatures and pressures. The results of this study are an increase in temperature and pressure in the anaerobic digestion process. Where the highest increase was found in the chemical composition on the 17th day until the 20th day with a temperature of $30 \square C$ and a maximum pressure of $18 \mathrm{~cm}=0.018 \mathrm{~N} / \mathrm{m} 2$ obtained from the difference in the water column. Organic composition with a temperature of $290 \mathrm{C}$ and a water column pressure difference of $17 \mathrm{~cm}=0.017 \mathrm{~N} / \mathrm{m} 2$. The lowest yield was found in a natural composition 
with a temperature of $260 \mathrm{C}$ with a water column difference of $4 \mathrm{~cm}=0.04 \mathrm{~N} / \mathrm{m} 2$. If biogas is not used, it will be produced for a long time.

Keywords: Tofu liquid waste, Variation in composition, Anaerobic digestion, Alternative energy.

\section{PENDAHULUAN}

Salah satu sumber energi alternatif terbarukan yang dapat dihasilkan dengan teknologi tepat guna yang relatif lebih sederhana, selain itu juga dapat dikembangkan karena bahan bakunya sangat berlimpah tersedia. Bahan umum yang dapat digunakan sebagai bahan baku biogas adalah limbah domestik (rumah tangga) atau kotoran ternak. Energi yang dihasilkan biogas berupa gas dari hasil proses fermentasi oleh bakteri dalam alat kedap udara (anaerobic) yang disebut biodigester. Biogas memiliki kandungan energi tinggi yang tidak kalah dari kandungan energi bahan bakar fosil. Nilai kalor dari $1 \mathrm{~m} 3$ biogas setara dengan 0,6 - 0,8 liter minyak tanah dan 0,46 kg gas elpiji. Untuk menghasilkan listrik $1 \mathrm{kwh}$ dibutuhkan 0,62-1 m3 biogas yang setara dengan 0,52 liter minyak solar[1].

Teknologi biogas merupakan salah satu teknik tepat guna untuk mengolah limbah, baik limbah peternakan, pertanian, limbah industri, dan rumah tangga untuk menghasilkan energi. Teknologi tersebut diantanya teknologi digester anaerob. Haryati dan Tuti menyatakan digester anaerob adalah proses yang ekonomis dan sangat menguntungkan baik dari segi keuntungan pengolahan limbah yang bersifat alami, membutuhkan lahan yang lebih kecil dibandingkan dengan proses kompos aerobic, memperkecil rembesan polutan, memperkecil volume atau berat limbah yang dibuang, dan dari segi keuntungan energi yang meliputi proses produksi energi yang bersih, berkualitas tinggi, dapat diperbaharui serta digunakan untuk berbagai keperluan. Sedangkan keuntungan dari segi lingkungan bahwa digester anaerobic dapat menurunkan emisi gas metana dan karbondioksida serta menghilangkan bau[2]. Teknologi pembuatan biogas dapat diaplikasikan sebagai sumber energi alternatif pengganti bahan bakar minyak dan secara tidak langsung juga membawa manfaat bagi lingkungan. Salah satu bahan baku pembentukan biogas diantaranya limbah cair tahu[3].

Selama ini limbah cair tahu sering dibuang secara langsung tanpa pengolahan 
terlebih dahulu sehingga menyebabkan terjadinya pencemaran air, seperti warna sungai menjadi keruh dan menghasilkan bau busuk dan mencemari sungai. Sumber limbah cair lainnya berasal dari pencucian kedelai, pencucian peralatan proses, pencucian lantai dan pemasakan serta larutan bekas rendaman kedelai. Jumlah limbah cair yang dihasilkan oleh industri pembuatan tahu kira-kira 15-20 1/kg bahan baku kedelai, sedangkan bahan pencemarnya kira-kira untuk TSS sebesar 30 $\mathrm{kg} / \mathrm{kg}$ bahan baku kedelai dan COD $130 \mathrm{~g} / \mathrm{kg}$ bahan baku kedelai[4].

\section{METODE PENELITIAN}

Penelitian ini dilakukan secara bertahap menggunakan variabel-variabel yang sudah ditentukan. Proses pengambilan data penelitian didapat selama proses optimasi berlangsung. Dalam penelitian ini adapun alur penelitian dari mulai mempersiapkan bahan hingga pengambilan data dapat digambarkan seperti gambar sebagai berikut :

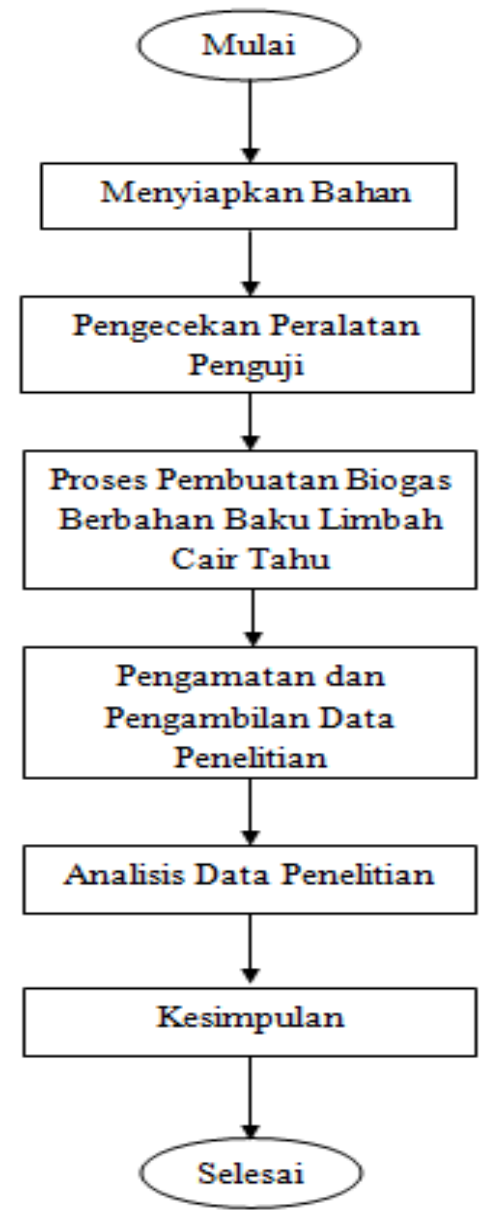

Gambar.1. Diagram Alur Penelitian 
Variabel-variabel yang digunakan dalam penelitian ini untuk mendapatkan data eksperimen adalah sebagai berikut

a. Variabel Bebas

Variabel yang digunakan dalam penelitian ini adalah sebagai berikut:

1) Variasi komposisi:

a) Komposisi Alami (Limbah cair tahu).

b) Komposisi Organik (Limbah cair tahu dan kotoran sapi).

c) Komposisi Kimia (Limbah cair tahu dan bioaktiva EM4).

2) Variasi waktu fermentasi:

a) Fermentasi 16 hari.

b) Fermentasi 17 hari.

c) Fermentasi 18 hari.

d) Fermentasi 19 hari.

e) Fermentasi 20 hari.

b. Variabel respon

Variabel respon yang digunakan pada penelitian ini adalah energi biogas yang dihasilkan yaitu : temperatur, tekanan

c. Variabel terkontrol

Variabel terkontrol dalam penelitian ini adalah lama/waktu fermentasi selama 20 hari.

Tahapan pengujian penelitian ini memaparkan langkah observasi penelitian deskriptif (penelitian yang dilakukan secara sistematis, teratur dan tertib) yang terdapat beberapa prosedur penelitian meliputi:

a. Mempersiapkan alat biodigester yang sudah terpasang termometer dan manometer.

b. Menyiapkan bahan baku limbah cair tahu 100 liter dan bahan campuran

c. Mempersiapakan limbah cair tahu ke dalam bak plastik dan campurkan bahan isian dengan perbandingan $1: 1$ yaitu : kotoran sapi $20 \mathrm{~kg}$, EM4 2 liter lalu aduk hingga rata.

d. Percobaan pertama masukkan bahan campuran ke dalam biodigester melalui lubang pemasukan.

e. Percobaan kedua campurkan limbah cair tahu dengan bioaktiva EM4 sebanyak 
2 liter, melalui lubang pemasukan.

f. Percobaan ketiga tidak ada bahan tambahan (alami) hanya limbah cair tahu.

g. Selanjutnya diamkan selama 20 hari agar terbentuk gas yang diinginkan.

h. Waktu pengambilan data dalam proses anaerobic digestion dilakukan pada hari ke 16, hari ke 17, hari ke 18, hari ke 19, hari ke 20.

Berikut adalah desain alat biodigester.

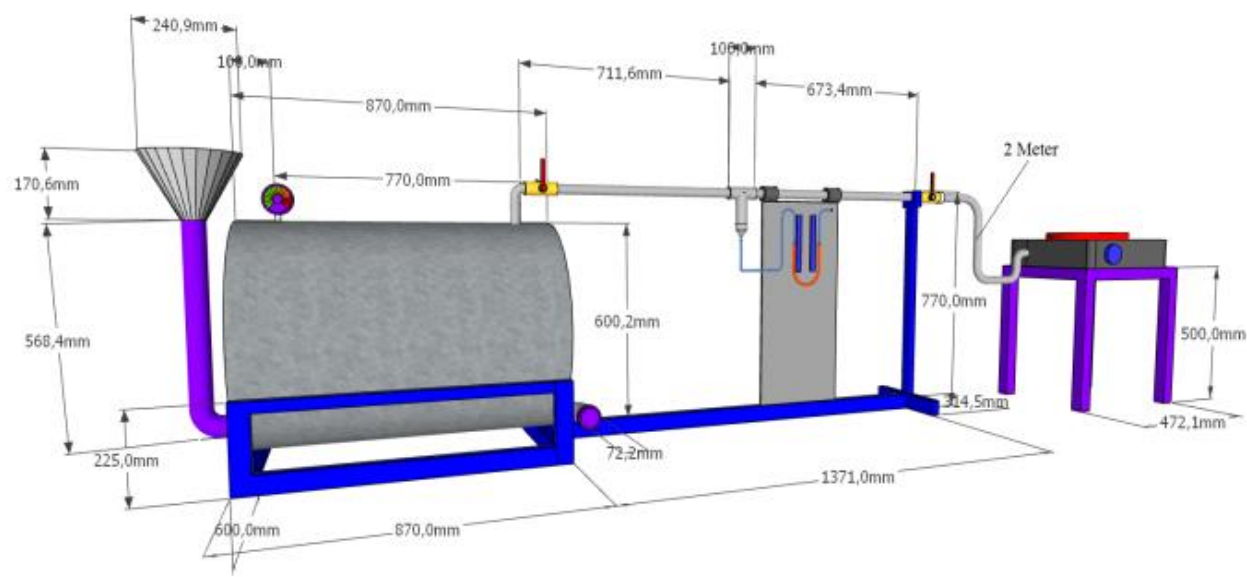

Gambar 2. Design biodigester

fungsi - fungsi bagian biodigester:

a. Saluran masuk bahan isian

Untuk memasukkan bahan baku isian (slurry) ke dalam digester.

b. Termometer bimetal

Alat bantu untuk mengukur suhu ruang di dalam digester.

c. Digester

Tempat untuk mengubah bahan baku limbah cair tahu menjadi gas methan dengan proses anaerobic digestion.

d. Saluran buang

Berfunsi untuk mengeluarkan residu sisa fermentasi.

e. Kran saluran biogas dan saluran keluar residu.

Kran saluran biogas berfungsi sebagai katup pengatur aliran gas dan kran saluran keluar residu berfungsi sebagai katub buka tutup residu sisa fermentasi.

f. Manometer Tabung U

Alat bantu untuk mengukur tekanan gas

g. Saluran biogas 
Untuk menyalurkan gas menuju kompor dan manometer tabung U.

h. Kompor

Kompor digunakan sebagai alat pembakar gas

\section{HASIL DAN PEMBAHASAN}

Data yang diperoleh selama penelitian dimasukkan ke dalam tabel penelitian sebagai berikut :

Tabel 1. Data hasil penelitian

\begin{tabular}{|c|c|c|c|c|}
\hline No. & Variasi komposisi & Hari fermentasi & $\begin{array}{l}\text { Suhu } \\
\left({ }^{\circ} \mathrm{C}\right)\end{array}$ & $\begin{array}{c}\text { Tekanan } \\
\left(\mathrm{N} / \mathrm{m}^{2}\right)\end{array}$ \\
\hline 1 & & 16 & 26 & $101.214,81$ \\
\hline 2 & & 17 & 26 & $101.223,52$ \\
\hline 3 & K.alami & 18 & 27 & $101.231,14$ \\
\hline 4 & & 19 & 28 & $101.343,41$ \\
\hline 5 & & 20 & 28 & $101.365,63$ \\
\hline 6 & & 16 & 26 & $101.266,42$ \\
\hline 7 & & 17 & 26 & $101.268,31$ \\
\hline 8 & K.organik & 18 & 28 & $101.471,35$ \\
\hline 9 & & 19 & 29 & $101.484,56$ \\
\hline 10 & & 20 & 29 & $101.491,77$ \\
\hline 11 & & 16 & 26 & $101.297,21$ \\
\hline 12 & & 17 & 26 & $101.297,21$ \\
\hline 13 & K.kimia & 18 & 29 & $101.487,24$ \\
\hline 14 & & 19 & 30 & $101.491,13$ \\
\hline 15 & & 20 & 30 & $101.501,58$ \\
\hline
\end{tabular}

Pengambilan data nilai tekanan biogas dibawah ini diambil dari data hari ke 16, hari ke 17, hari ke 18, hari ke 19, hari ke 20 dari setiap percobaan yang dilakukan sebagai berikut:

Komposisi Alami (20 hari terakhir)

Diketahui : $\quad \rho=1000 \mathrm{~kg} / \mathrm{m} 3$

$$
\begin{aligned}
& \mathrm{g}=9,81 \mathrm{~m} / \mathrm{s} 2 \\
& \mathrm{~h}=0,4 \mathrm{~cm}=0,004 \mathrm{~m} \\
& \mathrm{P} \text { atm }=101325 \mathrm{~N} / \mathrm{m} 2
\end{aligned}
$$


Ditanya : $\quad$ Po $=\ldots$. ?

Jawab : $\quad$ Po $=\rho \cdot g \cdot h+P$ atm

$=(1000 \mathrm{~kg} / \mathrm{m} 3 \cdot 9,81 \mathrm{~m} / \mathrm{s} 2 \cdot 0,004 \mathrm{~m})+101325 \mathrm{~N} / \mathrm{m} 2$

$=39,24+101325$

$=101.364,24 \mathrm{~N} / \mathrm{m} 2$

Komposisi Organik (20 hari terakhir)

Diketahui : $\quad \rho=1000 \mathrm{~kg} / \mathrm{m} 3$

$\mathrm{g}=9,81 \mathrm{~m} / \mathrm{s} 2$

$\mathrm{h}=17 \mathrm{~cm}=0,0017 \mathrm{~m}$

$\mathrm{P}$ atm $=101325 \mathrm{~N} / \mathrm{m} 2$

Ditanya : $\quad$ Po $=\ldots$. ?

Jawab : $\quad$ Po $=\rho \cdot g \cdot h+P$ atm

$=(1000 \mathrm{~kg} / \mathrm{m} 3 \cdot 9,81 \mathrm{~m} / \mathrm{s} 2 \cdot 0,0017 \mathrm{~m})+101325 \mathrm{~N} / \mathrm{m} 2$

$=166,77+101325$

$=101.491,77 \mathrm{~N} / \mathrm{m} 2$

Komposisi Kimia (20 hari terakhir)

Diketahui : $\quad \rho=1000 \mathrm{~kg} / \mathrm{m} 3$

$\mathrm{g}=9,81 \mathrm{~m} / \mathrm{s} 2$

$\mathrm{h}=18 \mathrm{~cm}=0,018 \mathrm{~m}$

$\mathrm{P}$ atm $=101325 \mathrm{~N} / \mathrm{m} 2$

Ditanya : $\quad$ Po $=\ldots .$. ?

Jawab : $\quad$ Po $=\rho \cdot g \cdot \mathrm{h}+\mathrm{P}$ atm

$$
=(1000 \mathrm{~kg} / \mathrm{m} 3 \cdot 9,81 \mathrm{~m} / \mathrm{s} 2 \cdot 0,018 \mathrm{~m})+101325 \mathrm{~N} / \mathrm{m} 2
$$$$
=176,58+101325=101.501,58 \mathrm{~N} / \mathrm{m} 2
$$

\section{KESIMPULAN}

Dari pembahasan yang diuraikan dalam tulisan ini, berdasarkan pengolahan hasil data eksperimen maka dapat diambil kesimpulan bahwaa :

1. Mekanisme pembuatan biogas dengan proses anaerobic digestion menggunakan bahan baku limbah cair tahu dengan biodigester berkapasitas 200 liter. Bahan baku limbah cair tahu dicampurkan dengan variasi komposisi yang berbeda ialah 
komposisi alami, komposisi organik dan komposisi kimia. Komposisi masingmasing berupa kotoran sapi 20 kg, cairan kimia EM4 2 liter dan alami dengan tidak ada penambahan. Bahan baku yang sudah dicampurkan selanjutnya dimasukkan ke dalam ruang digester. Lamanya waktu fermentasi selama 20 hari hingga di dapatkan data penelitian mengenahi temperatur dan tekanan biogas.

2. Ada pengaruh terhadap variasi komposisi bahan campuran dari temperatur dan tekanan biogas selama proses fermentasi 20 hari. Dimana peningkatan tertinggi terdapat pada komposisi kimia pada hari ke 17 hingga hari ke 20 dengan temperatur $30 \square \mathrm{C}$ dan tekanan maksimum adalah $18 \mathrm{~cm}=0,018 \mathrm{~N} / \mathrm{m} 2$ diperoleh dari selisih kolom air. Komposisi organik dengan temperatur $29 \square \mathrm{C}$ dan tekanan selisih kolom air $17 \mathrm{~cm}=0,017 \mathrm{~N} / \mathrm{m} 2$. Hasil terendah terdapat pada komposisi alami dengan temperatur $26 \square \mathrm{C}$ dengan tekanan selisih kolom air $4 \mathrm{~cm}=0,04$ $\mathrm{N} / \mathrm{m} 2$. Jika tidak menggunakan bahan campuran maka biogas akan lama diproduksi.

\section{DAFTAR PUSTAKA}

[1] Wahyuni. S. 2011. Biogas dari Aneka Limbah. Jakarta: Agromedia Pustaka. commit to user

[2] Haryati \& Tuti. 2006. Biogas Limbah Peternakan yang Menjadi Sumber Energi Alternatif. Wartazoa. Vol. 16, No. 3.

[3] Wahyuni \& Sri.Biogas Energi Alternatif Pengganti BBM, Gas, dan Listrik. Jakarta: Agro Media Pustaka, 2013.

[4] EMDI - Bapedal. 1994. Limbah Cair Berbagai Industri di Indonesia, tersedia :https//www.google.co.id. Diunduh 20 Oktober 2017. Sumber:Pengendalian dan Baku Mutu, EMDI - Bapedal 